
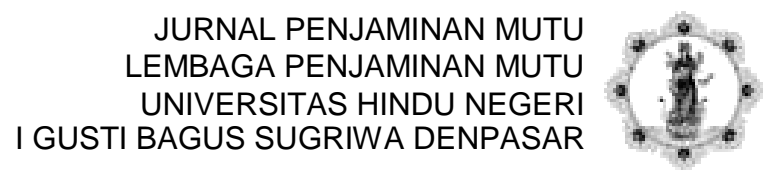

Volume 7 Nomor 22021

ISSN : 2407-912X (Cetak)

ISSN : 2548-3110 (Online)

http://ejournal.ihdn.ac.id/index.php/JPM

\title{
PEMAHAMAN AJARAN TAT TWAM ASI SEBAGAI PEDOMAN DALAM UPAYA PENINGKATAN MAWAS DIRI DI ERA PANDEMI COVID-19
}

\author{
Oleh \\ Ni Nyoman Suastini' ${ }^{1}$ I Ketut Budi Rach Suarjaya ${ }^{2}$ \\ ${ }^{12)}$ Universitas Hindu Negeri I Gusti Bagus Sugriwa Denpasar \\ ninyomansuastini62@yahoo.com ${ }^{1}$, budirasu@yahoo.co.id ${ }^{2}$
}

diterima 7 Juli 2021, direvisi 18 Agustus 2021, diterbitkan 31 Agustus 2021

\begin{abstract}
Abstrak
Peran Tat Twam Asi sangatlah penting bagi kehidupan yang harmonis dan damai. Dari lingkup yang paling kecil dalam sebuah keluarga hingga lingkup yang lebih besar, yaitu dalam sebuah negara, bahkan di dunia. Kehidupan yang damai tidak mungkin dapat diwujudkan tanpa adanya toleransi yaitu sikap saling menghormati, menghargai, memahami, maupun saling menerima adanya perbedaan yang ada. Karena perbedaan adalah sebuah keniscayaan yang tidak dapat kita hindari. Susastra Suci Weda mengajarkan tentang sebuah nilai yang dapat kita terapkan dalam kehidupan sehari-hari sebagai upaya mewujudkan kehidupan yang rukun dan damai. Sebuah nilai luhur yang harus dilestarikan dan patut kita tumbuh suburkan dalam sikap hidup keseharian kita. Ajaran Tat Twan Asi merupakan dasar dari Tata Susila Hindu di dalam usaha untuk mencapai perbaikan moral. Susila adalah tingkah laku yang baik dan mulia untuk membina hubungan yang selaras dan seimbang serta rukun di antara sesama. Sebagai landasan dalam membina hubungan yang selaras, maka kita dapat mengimplementasikan ajaran Tat Twan Asi ini dengan dengan beberapa cara: 1) Melakukan perbuatan yang sesuai dengan ajaran agama maupun norma yang berlaku dalam masyarakat yang timbul dari hati kita sendiri (bukan merupakan paksaan). 2) Bertanggung jawab atas segala tindakan yang kita lakukan. 3) Lebih mendahulukan kepentingkan bersama dari pada kepentingan pribadi.
\end{abstract}

\section{Kata kunci : Tat Twam Asi, Susila}

\section{PENDAHULUAN}

Agama memiliki peran yang amat penting dalam kehidupan umat manusia. Agama menjadi pemandu dalam upaya untuk mewujudkan suatu kehidupan yang bermakna, damai dan bermartabat. Menyadari peran agama amat penting bagi kehidupan umat manusia maka internalisasi agama 
dalam kehidupan setiap pribadi menjadi sebuah keniscayaan, yang ditempuh melalui pendidikan baik pendidikan di lingkungan keluarga, di lembaga pendidikan formal maupun nonformal serta masyarakat.

Pendidikan Agama dimaksudkan untuk membentuk manusia yang beriman, bertakwa kepada Tuhan Yang Maha Esa dan berakhlak mulia serta untuk meningkatan potensi spiritual masing-masing individu. Akhlak mulia yang dimaksud mencakup etika, budi pekerti, dan moral sebagai perwujudan dari Agama. Peningkatan potensi spritual mencakup pengenalan, pemahaman, dan penanaman nilai-nilai keagamaan, serta pengamalan nilai-nilai tersebut dalam kehidupan individual ataupun kolektif kemasyarakatan. Peningkatan potensi spritual tersebut pada akhirnya bertujuan pada optimalisasi berbagai potensi yang dimiliki manusia yang aktualisasinya mencerminkan harkat dan martabatnya sebagai makhluk Tuhan (Lilik \& Mertayasa, 2019).

Dalam ajaran Agama Hindu dikenal dengan tiga kerangka dasar yang sangat diyakini sebagai pedoman hidup umat-Nya, di mana bagian yang satu dengan lainnya saling mengisi menjadi satu kesatuan yang bulat, sehingga dapat dihayati, dan diamalkan untuk mencapai tujuan yang disebut Moksa. Tiga kerangka dasarnya, yaitu: (1) tattwa, (2) susila, dan (3) upacara. Ketiganya secara sistematik merupakan satu kesatuan yang saling memberi fungsi atas sistem agama Hindu secara keseluruhan. Tattwa adalah aspek pengetahuan agama atau ajaran-ajaran agama yang harus dimengerti dan dipahami oleh masyarakat terhadap aktivitas keagamaan yang dilaksanakan. Susila adalah aspek pembentukan sikap keagamaan yang menuju pada sikap dan perilaku yang baik sehingga manusia memiliki kebajikan dan kebijaksanaan, wiweka jnana, sedangkan Upacara adalah tata cara pelaksanaan ajaran agama yang diwujudkan dalam tradisi upacara sebagai wujud simbolis komunikasi manusia dengan Tuhannya.

Ketiganya tidak dapat berdiri sendiri, tetapi merupakan suatu kesatuan yang harus dimiliki dan dilaksanakan oleh umat Hindu.
Jika filsafat agama saja yang diketahui tanpa melaksanakan ajaran-ajaran susila dan upacara, tidaklah sempurna. Demikian juga jika hanya melaksanakan upacara saja tanpa tanpa dasar-dasar filsafat dan etika, percuma pulalah upacara-upacara itu. Jadi ketiga hal itu tidak dapat dipisah-pisahkan, sebagai halnya kepala, hati, dan kaki yang tak dapat dipisahkan untuk membentuk manusia sempurna. Tattwa sebagai kepala, Susila sebagai hati, dan upacara sebagai tangan kaki agama. Dapat juga diandaikan sebagai sebuah telor; sarinya ialah tattwa, putih telornya sebagai susila, dan kulitnya adalah upacara. Telor ini tidak sempurna dan akan busuk jika salah satu dari bagian tersebut tidak ada atau lengkap.

Di era pandemi yang tak kunjung berakhir ini sangatlah perlu bagi seluruh umat manusia pada umumnya dan umat Hindu khususnya untuk memahami akan pentingnya rasa saling mengasihi antara sesama mahluk hidup. Kehidupan yang harmonis dan damai tentu menjadi impian dan juga harapan bagi semua orang. Dari lingkup yang paling kecil dalam sebuah keluarga hingga lingkup yang lebih besar, yaitu dalam sebuah negara, bahkan di dunia. Kehidupan yang damai tidak mungkin dapat diwujudkan tanpa adanya toleransi yaitu sikap saling menghormati, menghargai, memahami, maupun saling menerima adanya perbedaan yang ada. Karena perbedaan adalah sebuah keniscayaan yang tidak dapat kita hindari.

Susastra Suci Weda mengajarkan tentang sebuah nilai yang dapat kita terapkan dalam kehidupan sehari-hari sebagai upaya mewujudkan kehidupan yang rukun dan damai. Sebuah nilai luhur yang harus dilestarikan dan patut kita tumbuh suburkan dalam sikap hidup keseharian kita. Dalam Chandhogya Upanishad VI.8.7 tersurat sebuah Maha Vakya atau semboyan utama yaitu Tat Twam Asi yang merupakan nilai yang sangat luhur, yang dapat kita gunakan sebagai pedoman dalam upaya peningkatan mawas diri sehingga dapat terwujud sebuah kehidupan yang rukun dan damai. Tat Twam Asi mengandung arti bahwa 'itu adalah engkau, engkau adalah dia'. Kata 
'itu' bermakna sebagai Brahman atau Sumber segala kehidupan. Sedangkan kata 'engkau' adalah merupakan Atman atau jiwa yang menghidupi semua makhluk. Dengan demikian dapat kita maknai bahwa jiwa yang bersemayam dalam setiap manusia adalah berasal dari sumber yang sama yaitu Brahman atau Tuhan sendiri. Ajaran Tat Twan Asi merupakan pedoman hidup yang harus diimplentasikan terlebih disaat seperti sekarang ini. Tat Twam Asi sebagai landasan dalam membina hubungan yang selaras, seimbang, rukun dan harmonis.

\section{PEMBAHASAN}

\subsection{Tat Twan Asi Sebagai Landasan Kesamaan Martabat}

Tat Twam Asi adalah ajaran kesusilaan tanpa batas yang merupakan filsafat Agama Hindu. Ajaran Tat twam Asi ini dinyatakan identik dengan sila keprimanusiaan dalam Pancasila. Dinyatakan pula bahwa jika di cermati secara sungguh - sungguh, konsepsi sila perikemanusiaan dalam pancasila merupakan realisasi dari ajaran Tat Twam Asi yang terdapat dalam Kitab Suci Weda. Dengan demikian dapat dikatakan bahwa mengkhayati dan mengamalkan Ajaran Pancasila sama artinya dengan melaksanakan ajaran Weda, karena maksud yang terkandung dalam Tat Twam Asi yakni " Ia adalah kamu, saya adalah kamu dan semua makluk adalah sama." Karena itu jika kita menolong orang lain, maka itu berarti bahwa kita menolong diri kita sendiri ( Sudirga dkk., 2004 : 106 - 107). Selanjutnya dijelaskan pula bahwa Tat Twam Asi merupakan ajaran moral yang bernafaskan Agama Hindu, yang wujud nyatanya dapat dilihat dari kehidupan masyarakat sehari - hari, serta perilaku keseharian dari padanya. Ajaran Tat Twam Asi dapat dilaksanakan dalam kehidupan sehari - hari secara sungguh - sungguh dan menyeluruh, maka kehidupan masyarakat akan menjadi sangat harmonis, saling menolong, saling menghargai dan saling menghormati, sehingga keadaan umat manusia akan menjadi aman dan damai.
Karena itu ajaran Tat Twam Asi perlu dijadikan pedoman dalam melaksanakan hidup sehari - hari.

Sementara menurut Sukartha dkk. ( 2002 : 67 ), Tat Twam Asi berasal dari bahasa Sansekerta yang tertuang dalam Chandogya Upanisad. Dijelaskan bahwa kata Tat berarti "Itu" atau "Dia" Twat Berarti "Engkau" atau "Kamu" dan Asi berarti "Adalah" jadi tat Twam Asi diartikan menjadi Dia Adalah Кати. Untuk lebih jelasnya dapat dilihat dari Chandogya Upanisad mengenai Tat Twam Asi

Sa ya eso'nima aitad atmyam idam sarwam, tat sasatyam, sa atma;tat twam asi,svetaketo iti bhuya eva ma,bhagavan,vijnapayatv iti, tatha,saumya, iti hovaca. Chandogya Upanisad VI.8.7

Artinya :

"Yang itu adalah sari paling halus atau akar dari semuanya,seluruh alam semesta

menjadikanya sebagai atmanya,itulah kebenaran. Itulah Atman Tat Twam Asi,"Svetaketu. "mohonlah junjunganku, ajarkanlah kepada hamba lebih jauh lagi." "baik-baiklah anakku" kata beliau

Tat Twam Asi Berarti "Itu Adalah Kamu" naskah tersebut menekankan sisi keutuhan dari jiwa manusia, untuk membedakan antara atman yang merupakan inti dengan kejadian- kejadian,dengan apa hal ini sering dikacaukan dan dengan apa hal ini terikat. Dia yang hanya mengerti apa yang ada dalam tubuh dan fikiran, hanya mengerti apa yang mungkin adalah menjadi miliknya, tetapi bukan dirinya sendiri. Ungkapan "Kamu adalah Aku" diterapkan pada makluk yang didalam,antah purusa dan tidak kepada jiwa empiris dengan nama dan 
keturunan keluarganya "Apa Aku ini, begitu juga Dia, begitu juga Aku."

Dijelaskan pula mengenai Jabala Upanisad yang berbunyi "Twam va aham asmi bhagavo devante aham va twam asi" Aku adalah Engkau,wahai Tuhan Yang Maha Agung dan Engkau Adalah Aku. Pernyataan ini menyimpulkan bahwa Tat Twam Asi sebagai penegasan bahwa jaran tuhan adalah sama baiknya pada alam semesta maupun individu. Ini berarti bahwa tuhan yang memiliki Atman Individu sebagai tubuhnya. Asas ketuhanan sama untuk keduanya.

\subsection{Ajaran Kesamaan Martabat Manusia}

Dari uraian diatas jelaslah bahwa Tat Twam Asi Berarti "Dia itu adalah Kamu" dengan kata lain dapat diartikan "Aku adalah kamu" atau "Kamu adalah Aku" dapat pula diartikan bahwa "Jiwaku adalah Jiwamu" inilah oleh Puja dijadikan ajaran kesamaan manusia. Atau lebih tepatnya Ajaran Kesamaan Derajat Manusia, Maksudnya bahwa manusia dilahirkan dengan derajat atau martabay yang sama. Karena itu manusia harus saling mencintai, saling menghargai. Cinta kasih antar sesame manusia ciptaan tuhan adalah sangat penting. Asas kesamaan martabat manusia ini perlu dipahami oleh umat manusia khususnya umat hindu. Bahwa kita diciptakan oleh Tuhan dengan derajat dan martabat yang sama.

Penjelesan diatas diharapakan dapat menyadarkan semua umat Hindu, betapa pentingya menghayati, memahami pengertian dan mengamalkan ajaran Tat Twam Asi. Sebagai ajaran kesamaan martabat manusia, seperti sudah disinggung diatas Tat Twam Asi berarti juga "Jiwaku sama dengan Jiwamu" atau "Jiwamu sama dengan Jiwaku" pernyataan ini barangkali sulit dimengerti. Secara fisik manusia itu memang berbeda. Tetapi atman yang ada pada diri manusia sebagai percikan sinar suci Tuhan Hyang Maha Esa adalah atman yang sama pada orang lain. Tuhan itu satu, Maha Esa. Tetapi percikan sinar sucinya berupa atman ada dimana - mana, ada di semua tubuh manusia, seperti sinar matahari yang menyebar keseluruh jagat raya. Jadi atman yang ada dalam diriku sama saja dengan atman yang ada dalam dirimu. Karena itu kita ini, umat manusia ini semua sesungguhnya adalah keluarag besar dunia, yang selalu harus hidup rukun,aman tentram dan damai, walaupun ada perbedaan pendapat, perselisihan dan percekcokan itulah pertanda bahwa mereka belum menghayati ajaran Tat Twam Asi, yang pada hakekatnya merupakan pedoman dasar untuk masyarakat Hindu bisa hidup harmonis, tolong menolong, saling menghormati, saling menghargai satu dengan yang lainya.

\subsection{Tat Twam Asi Dalam Kitab Suci Weda}

Tat Twam Asi pada dasarnya adalah Ajaran Cinta Kasih Terhadap Sesama Makluk Ciptaan Tuhan.Dengan pengertian "Saya adalah Kamu" atau "Kamu adalah Saya," "Jiwamu adalah Jiwaku" dan "Jiwaku adalah Jiwamu" maka ajaran Tat Twam Asi merupakan ajaran persahabatan dan ajaran persahabatn atau persaudaraan yang harmonis diantara keluarga besar dunia dengan tujuan dapat tercapainya kerukunan dan ketertiban dalam masyarakat. Tat Twam Asi adalah ajaran kesamaan martabat manusia.

Dalam Kitab Suci Weda banyak sekali terkandung nilai - nilai Tat Twam Asi. Diantaranya adalah sebagai berikut :

\section{Kebijakan atau Kemurahan Hati}

Tuhan memberikan petunjuk kepada manusia agar selalu bermurah hati dan suka menolong, disamping dermawan. Orang yang dermawan akan memproleh kemuliaan

\section{Ucca divi daksinavanto asthur \\ Ye asvadah saha te suryena Rgveda X.107.2}

\section{Artinya :}

Orang - orang dermawan akan menghuni tempat yang tinggi di sorga.

\section{Daksinavanto amrtam bhajante Daksinavantah pra tiranta ayuh Rgveda I.125.6 \\ Artinya :}


Orang - orang yang bermurah hati akan mencapai keabadian Mereka memperpanjang

hidupnya

\section{Keluhuran Budi :}

Keluhuran budi hanya bisa tercipta dengan perbuatan baik dan mulia. Dengan menolong orang miskin dan membantu dalam pendidikan bagi anak - anak yang tidak mampu,dapat dapat mengembangkan keluhuran budi.

Daksinaswam daksina gam dadati

Daksina candram uta yad hirayam

Daksina annam vanute yo $n$ atma

Daksinam varama krnute vijanam

X.107.7

Rgveda

Artinya :

Dana punia sebagai persembahan tulus iklas

Akan memberikan imbalan yang melimpah

Jiwa kita mengetahui hal itu dengan baik

Pakailah kemurahan hati sebagai pelindung.

\section{Kebijakan Jalan yang Benar}

Manusia hendanya selalu mengikuti jalan yang benar, jalan kebajikan. Siapa saja yang berjalan di jalan yang benar dipastikan akan memproleh kemakmuran,jasa dan kebajikan. Untuk itu dekatkanlah diri kepada Tuhan agar selalu memproleh bimbingan Nya. Dengan meyakini jalan kebenaran, maka kebajikanya akan melenyapkan kesusahan.

Svasti pantham anu carema

Surya candramasav iva

Punar dadataghnata

Janata sam gamemahi

Rgveda V.51.15
Mari berjalan pasa jalan yang benar

Seperti jalannya matari dan bulan

Bergaullah dengan orang orang yang murah hati

Dan orang yang berpengetahuan tinggi.

\section{Keserasian Jalan Menuju Kerukunan}

Dengan keserasian hidup, kemakmuran dan persatuan akan dapat dicapai keserasian hendaknya dirimtis dalam lingkungan keluarga, kemudian kedalam masyarakat sekitar. Keserasian menjadikan kita hidup rukun dan damai.

Sam vo manamsi sam vrata

Sam akutir namamasi

Ami ye vivrata sthana

Tan vah dam samayamasi

Atharvaveda III.8.5

Artinya :

Tuhan menyatukan fikiran, tindakan dan gagasan

Tuhan mengantarkan penjahat kejalan yang benar

Agar semuanya menjadi selaras dan sejahtera

\subsection{Tat Twam Asi Dalam Kitab Manawa \\ Dharmasastra}

Untuk dapat melaksanakan ajaran Tat Twam Asi dengan baik, pengendalian memegang peranan yang sangat penting. Pengendalian dalam hal ini dimaksudkan sebagai usaha untuk membebaskan diri dari masalah - masalah keduniawian. Hanya dengan pengendalian diri kita dapat bersahabat dengan baik dengan siapa saja. Kendalikanlah fikiran, perkataan dan perbuatan itu dengan baik, maka segala keingin dapat tercapai, terutama dalam memlihara pertemanan dengan sesama.

Kitab Manawa Dharmasastra mengatakan :

Indrayanam parangsanggena 
Dosamrccatysamcayam

Samniyamya tu tnyewa

Tatah siddhim niyacchati

Manawa dharmasastra II.93

Artinya :

Karena keterikan dengan

keduaniawian

Mananusia tanpa ragu pasti berbuat dosa

Tetapi jika mampu mengendalikan diri

Ia akan berhasil dengan segala tujuannya

Indriyasamyamasya sarwe

purusartha

Hekutam darcayati

Wace krtwendriya gramam

Samyamya ca manasthatha

Sarwam samsa dhayed artha

Na ksinwanyogatastanun

Manawa Dharmasastra II.100

Artinya :

Jika semua indria telah dikendalikan

Seperti juga fikiran sudah terkendali

Maka semua yang diinginkan akan tercapai

Tanpa perlu melaksanakan yoga

Dalam memelihara persaudaraan dan kasih sayang sesama manusia sesuai dengan ajaran Tat Twam Asi, maka umat manusia perlu menyesuaikan perkataan dan fikiranya. Apa yang kita fikirkan itu semestinya yang kita dikatakan. Dan fikiran itu tentunya hanya mengenai hal - hal yang baik baik saja. Hanya dengan demikian kita dapat memelihara persuadaraan kita itu dengan baik.

Yang dijelaskan dalam Manawa Dharmasastra

Wayasah karmano'rthasya

Crutasyabhijanasya ca

Wesawag buddhi sarupyam

Acaran wicarediha

Manawa Dharmasastra IV.18

Artinya :
Berjalan Didunia ini hendaknya menyesuaikan

Pakaikan, kata - kata, serta fikiran agar sesuai

Sesuai dengan kedudukan dan kekayaanya

Sesuai pelajaran suci dan kewangsaanya

\subsection{Tat Twam Asi Dalam Kitab \\ Sarasmucaya \\ Seperti dalam kitab - kitab Suci Hindu} lainya, dalam Kitab Sarasmucayapun dapat ditemukan adanya Sloka - Sloka yang pada hakekatnya mendukung pelaksanaan ajaran Tat Twam Asi.

\section{Jangan Menyimpang Dari Ajaran Dharma}

Terhadap semua orang yang sesungguhnya adalah saudara kita juga, hendaknya kita tidak berfikir, berkata ataupun berbuat yang tidak baik, apalagi yang dapat menyakiti atau menyebabkan kesusahan dan sakit hati orang lain. Dinyatakan pula bahwa orang yang jujur dan selalu berkata benar akan berhasil mengendalikan keinginannya. Selalu melaksanakan ajaran Dharma. Hal ini dinyatakan dalam Sloka-Sloka

Sloka 41

Na tata parasya sandadhayat

Pratikulam yadatmanah

Esa samksepato dharma

Kamadanyat prawartate

Artinya :

Berbuatan.kata-kata dan fikiran yang tak enak

Bahklan menimbulkan kesusahan dan sakit hati

Yang seperti itu jangan dilakukan kepada orang lain

Itulah dharama namanya, jangan menyimpang

Sloka 42

Ye tu cista suniyatah

Satyarjawaparayanah

Dharamyam panthanamarudhas

Tesam prttam samacara 
Artinya :

Orang bijaksana, jujur,berkata-kata benar Berhasil mengalahkan hawanapsunya Tulus iklas lahir batin, dharmalah maknanya

Jika dapat mengikutinya itulah dharma prawrtti

\section{Kendalikan fikiran, perkataan dan perbuatan}

Untuk berfikir, berkata dan berbuat baik terhadap semua manusia yang sebenarnya merupakan saudara kita juga, maka kita perlu melaksanakan pengendalian diri. Meliputi sepuluh pengendalian indria, tiga pengendalian fikiran, empat pengendalian perkataan, dan tiga pengendalian fikiran. Tiga pengendalian fikiran meliputi tidak menginginkan dan dengki atas milik orang lain, tidak marah kepada semua makluk, percaya atas kebenaran ajaran Karma Phala. Sedangkan empat pengendalian perkataan mencakup tidak boleh berkata jahat, tidak boleh berkata kasar atau menghardik, tidak boleh memfitnah dan tidak boleh berbohong. Membunuh, mencuri dan berzina adalah tiga perbuatan yang tidak patut dilakukan. Sloka - Sloka dibawah ini menyatakan :

\section{Sloka 73}

Mansa triwidham caiwa

Waca caiwa caturwinham

Kayena triwidham capi

Dacakarma pathaccaret

Artinya :

Sepuluh pengendalian indria harus dijalankan

Pengendalian fikirin tiga banyaknya

Pengendalian perkataan empat banyaknya Pengendalain perbuatan tiga banyaknya

Sloka 77

Kayena manasa waca

Yad abhiksanam nisewyate

Tadewapaharatyenam tasmat

Kalyanam acaret
Artinya :

Inilah yang menyebabkan orang dikenal Pikiranya, tingkahlakunya, dan ucapanya Hal itulah yang perlu diperhatikan manusia

Biasakan berfikir, berbuat dan berkata yang baik

\section{Tinggalkan Sifat Dengki dan Irihati}

Yang perlu dilakukan dalam menjaga hubungan kita tidak boleh dengki, irihati dan menginginkan milik orang lain. Sebab ini merupakan sifat yang harus dibuang jauh - jauh. Yang perlu dilakukan adalah menjaga cinta kasih kepada semua makluk, disamping perlu juga menjaga pengendalian diri agar tidak melanggar larangan Ajaran Agama.

Sloka 88

Dalam sloka dibawah ini dijelaskan :

Abhidhyaluh paraswesu neha

Namutra nandati

Tasmadabhidhya santyajya

Sarwadabhipsata sukham

Artinya :

Dengki dan menginginkan milik orang lain

Orang demikian tidak akan mendapatkan kebahagiaan

Tinggalkan sifat - sifat buruk seperti itu Jika menginginkan kebahagiaan abadi

Sloka 89

Sada samahitam citta naro

Bhutesu dharayet

Nabhidhyayenne sprhayenna

Baddham cintayed asat

Artinya :

Inilah yang patut diperbuat orang

Cinta kasih kepada semua makluk

Jangan dengki dan menginginkan barang orang

Jangan berangan - angan buruk seperti itu

\section{Kesabaran Adalah Kekayaan Yang Utama}

Dalam membina hubungan dengan siapapun, maka kesabaran adalah yang 
paling utama. Denganhati yang sabar maka kemarahan dan pertengkaran akan dapat dihindarkan. Sloka - Sloka dibawah ini menyatakan :

\section{Sloka 93}

Natah crimatta kincidayat

Pathyatara tatha

Prabhawisnorytha tata ksama

Sarwatra sarpwada

Artinya :

Kesabaran itu kekayaan yang paling utama

Bagi orang mampu mengatasi nafsu

Tidak ada yang melebihi kemulianya

Sebagai landasan tercapainya keinginan

\section{Sloka 95}

Yah samutpatitam krodham

Ksamaya iwa nirasyati

Yathoragastwacam jirnam sa

Wai purusa ucyate

Artinya :

Jika ada yang meninggalkan kemarahan

Yang dilandasi hati yang sabar

Itulah orang yang berbudi luhur

Yang patut desebut manusia sejati

\subsection{Tat Twam Asi Dalam Kitab \\ Slokantara}

Kitab Slokantara juga berisi nilai - nilai bagaimana sebaiknya manusia harus bersikap untuk menciptakan rasa kasih sayang terhadap sesama. Tat Twam Asi sebagai sebagai ajaran kesamaan manusia menyatakan bahwa semua umat manusia itu pada dasarnya adalah bersaudara, karena semua atman kita bersumember dari satu, sumber yang sama yakni Tuhan Yang Maha Esa. Berikut ini adalah beberapa sloka Kitab Slokantara :

\section{Kebenaran Kewajiban Suci Tertinggi : \\ Menciptakan rasa kasih} sayang kepada sesama manusia, tentu harus didasarkan kepada Ajaran Dharma atau Ajaran Agama. Diantara berbagai ajaran Dharma, maka kebenaran ( satya ) menempti posisi yang tertinggi. Tidak ada yang menyamai ketinggian kebenaran. Kebenaran adalah yang paling utama, seperti dinyatan dalam Kitab Slokantara :

Sloka I

Brahmano wa manusyanam

Adutyo wapi tejasam

Siro wa sarwagatresu

Dharmesu satyam uttamam

Artinya :

Seperti Brahmana diantara manusia

Matahari diantara sumber cahaya

Kepala diantara angota badan

Demikianlah kebenaran paling utama

\section{Kebenaran Sumber Menuju Kesempurnaan Hidup}

Ajaran Dharma juga menyatakan bahwa kebenaran adalah hukum hidup manusia. Karena itu kebenaran dikatakan sebagai sumber dan jalan menuju kesempurnaan hidup.

Kembalikanlah kekuatan anda kebawah kekuasaan kebenaran. Simaklah Sloka Kitab slokantara berikut :

Sloka 3

Nasti satyat paro dharmo

Nanrtat patakam param

Triloke ca hi dharma syat

Tasmat satyam na lopayet

Artinya :

Tiada dharma yang lebih tinggi dari kebenaran

Tiada dosa yang lebih rendah dari dusta

Dharma harus dilaksanakan

Kebenaran hendaknya tidak dilanggar.

\section{Hanya Kebenaran Yang Langgeng} kasih sayang itu? didunia ini sesungguhnya tidak ada Mengapa kebenaran menjadi landasan untuk mencapai yang langgeng kecuali kebenaran. Kekayaan tidak langgeng, keremajan dan cinta kasihpun tidak kekal. Yang kekal adalah perbuatan atau karma 
yang baik dan yang buruk karena itu manusia hendaknya selalu berpegang kepada kesusilaan atau perbuatan yang baik, berpegang kepada kebenaran itu. Kitab Slokantara menyatakan. Kitab Slokantara menyatakan:

Sloka 4

Anityam yauwanam

Rupamanityo drawyasamcayah

Anityah priyasamyogastasmad

Dharmam samacaret

Artinya :

Keremajaan dan Kecantikan itu tidak kekal

Kekayaan itu juga tidak langgeng

Hubungan dengan kekasihpun tidak kekal

Carilah kebenaran karena itulah yang langgeng

\section{Berusahalah Berbuat Baik :}

Untuk memelihara persaudaraan dan perhabatan dalam pengertian saling menghargai, saling menghormati dan saling menolong, sesuai ajaran Kesamaan, manusia hendaknya menghindarkan diri dari perbuatan yang tidak baik, dari prilaku yang mengantarkannya ke Neraka. Semua manusi hendaknya harus berbuat baik untuk mengantarkan ke Sorga. Perhatikanlah Sloka Kitab Slokantara sebagai berikut :

Sloka 5

Trnakusamuditanam kancanaih mrganam Phalatarumuditanam ratnabhirwanaram Asurabhimmuditanam naranamtu priyam taswisesam

Artinya :

Kijang perlu rumput muda, bukan emas Kera perlu buah-buahan,bukan mutiara Babi perlu makanan busuk, bukan bunga Bagi manusia berbuat baiklah yang utama

Sloka 16

Gawasananam sa girah sronoti

Aham tu rajam muninam sronomi
Pratyaksamentad bhawatapi drestham

Samsargaja dosaguna bhawanti

Artinya :

Dia dengar nasehat pemakan daging sapi

Hamba mendengarkan nasehat orang suci

Baik atau buruk sifat kelakuan manusia

Jelas ditentukan oleh pergaulanya

\section{Sloka XIII.1}

Muhurtamapi jivecca

Narah suklena karmana

Na kalpamapi kastena

Loka dvaya virodhina

Artinya :

Walau menikmati hidup hanya sesaat

Tetapi kalau dipakai untuk berbuat baik

Itu masih lebih baik dari pada

Hidup lama tetapi menderita terus

\subsection{Tat Twam Asi Dalam Kitab Niti Sastra}

Mencari nilai - nilai kasih sayang ajaran Tat Twam Asi dalam Kitab-Kitab Suci Agama Hindu tidaklah sulit. Semua kitab Suci Hindu pada hakekatnya adalah sumber ajaran kasih sayang, sumber ajaran kesamaan manusia dan sumber ajaran persaman derajat. Kitab Niti Sastra dibawah ini juga mengandung nilai-nilai ajaran persamaan derajat yaitu :

\section{Janganlah Iri Hati}

Disebutkan dalam Sloka Kitab Niti Sastra

Sloka V.6

Mukhanam pandita dvesya

Adhananam mahadhanah

Durbhaganam ca subhagah

Kulatanam ulangganah

Artinya :

Orang bodoh irihati kepada orang bijaksana

Orang miskin irihati kepada orang kaya

Janda irihati kepada wanita yang ad suaminya

Wanita jahat irihati kepada wanita berbudi luhur 


\section{Sebelum Berbuat Fikirkanlah Akibatnya}

Berbicara atau berbuat kepada atau dengan saudara dan siapapun jugamemang tidak sulit, tetapi jangalah berbuat dan berbicara sembarangan. Pikirkanlah dulu dengan baik apa akibat dari yang akan dibuat atau dibicarakan. Kitab Niti Sastra dibawah ini menyatakan :

Sloka X.2

Drsiputam nyasetpadam

Vastra putam pibejjalam

Sastra putam vaded vakyam

Manah putam samacaret

Artinya :

Lihat dulu dengan teliti baru berjalan

Jika minum air, saringlah dulu

Mengerti dulu Kitab Suci, baru bicara

Pikirkan dulu matang - matang baru berbuat

\section{Perbanyaknyalah Perbuatan \\ Dharma dan Kebenaran}

Sebagai manusia yang memahami Asas Kesamaan, kita harus selalu mengikuti ajaran Agama dengan berbegang kepada kebenaran. Manusia itu umurnya pendek, karena itu berbuat baiklah selalu sebagai bekal untuk menuju kematian. Demikain dinyatakan dalam Sloka Kitab Niti Sastra dibawah ini :

Sloka XII.12

Anityani sarirani

Vibhavo naiva sasvatah

Nityam sannihito mrtyuh

Kartavyo dharma samgrahah

Artinya :

Badan ini tidak kekal

Kekayaan juga tidak kekal

Seangkan kematian amat dekat

Perbanyaklah kegiatan Dharma / Kebenaran

\section{Kendalikanlah Pikiran :}

Kalau kita ingin bersahabat atau bersudara dengan baik untuk dapat mengikuti Ajaran Kesamaan atau Tat Twam Asi, maka kendalikanlah pikiran itu, sedab fikiran dapat menyebabkan orang menjadi baik atau sengsara. Pikiran dapat Mengakibatkan orang terikat akan sesuatu. Sebaliknya jika pikiran tidak terikat dengan keduniawian, maka moksa atau pembebasan adalah Phalanya.dinyatakan dalam Kitab Niti Sastra berikut ini :

Sloka XIII.12

Bandhaya visayad sanggo

Muktau nirvisayam manah

Mukatu nirvisayam manah

Mana eva manusyanam

Karanam bandha moksayoh

Artinya :

Pikiran terikat kepuasan penyebab keterikatan

Pikiran tak terikat kepuasan penyebab pembebasan

Pikiranlah menyebabkan manusi itu terikat

Pikiran pula menyebabkan mencapai pembebasan

Sloka XIII.18

Karmayattam phalam pumsam

Buddhih karmanusarini

Tathapi sudhisyacaryah

Suvicaryaiva kurvate

Artinya :

Orang menikmati hasil dari perbuatanya

Kecerdasan diperoleh dari perbuatan terdahulu

Karena itulah para acarya atau guru guru suci

Melakukan Sesutu setelah difikir matang - matang

Sloka XIV.12

Sa jivati guna yasya 
Yasyah dharmah sa jivati

Guna dharma vihinasya

Jivitam nisprayojanam

Artinya :

Yang memiliki sifat baik, dia hidup

Yang melaksanakan ajaran Dharma, dia hidup

Yang tidak memiliki sifat baik, tidak

bertindak

Berdasarkan dharma, hidup tidak berguna

\subsection{Tat Twam Asi Sebagai Pedoman Dalam Upaya Peningkatan Mawas Diri}

Seperti yang telah dijabarkan diberbagai kitab suci agama Hindu, peran Tat Twam Asi sangatlah penting bagi kehidupan yang harmonis dan damai. Dari lingkup yang paling kecil dalam sebuah keluarga hingga lingkup yang lebih besar, yaitu dalam sebuah negara, bahkan di dunia. Kehidupan yang damai tidak mungkin dapat diwujudkan tanpa adanya toleransi yaitu sikap saling menghormati, menghargai, memahami, maupun saling menerima adanya perbedaan yang ada. Karena perbedaan adalah sebuah keniscayaan yang tidak dapat kita hindari.

Susastra Suci Weda mengajarkan tentang sebuah nilai yang dapat kita terapkan dalam kehidupan sehari-hari sebagai upaya mewujudkan kehidupan yang rukun dan damai. Sebuah nilai luhur yang harus dilestarikan dan patut kita tumbuh suburkan dalam sikap hidup keseharian kita.

Dalam Chandhogya Upanishad VI.8.7 tersurat sebuah Maha Vakya atau semboyan utama yaitu Tat Twam Asi yang merupakan nilai yang sangat luhur, yang dapat kita gunakan sebagai pedoman dalam membangun sebuah kehidupan yang rukun dan damai. Tat Twam Asi mengandung arti bahwa 'itu adalah engkau, engkau adalah dia'. Kata 'itu' bermakna sebagai Brahman atau Sumber segala kehidupan. Sedangkan kata 'engkau' adalah merupakan Atman atau jiwa yang menghidupi semua makhluk. Dengan demikian dapat kita maknai bahwa jiwa yang bersemayam dalam setiap manusia adalah berasal dari sumber yang sama yaitu Brahman atau Tuhan sendiri.

Ajaran Tat Twan Asi merupakan dasar dari Tata Susila Hindu di dalam usaha untuk mencapai perbaikan moral. Susila adalah tingkah laku yang baik dan mulia untuk membina hubungan yang selaras dan seimbang serta rukun di antara sesama.

Sebagai landasan dalam membina hubungan yang selaras, maka kita dapat mengimplementasikan ajaran Tat Twan Asi ini dengan dengan beberapa cara: 1) Melakukan perbuatan yang sesuai dengan ajaran agama maupun norma yang berlaku dalam masyarakat yang timbul dari hati kita sendiri (bukan merupakan paksaan). 2) Bertanggung jawab atas segala tindakan yang kita lakukan. 3) Lebih mendahulukan kepentingkan bersama dari pada kepentingan pribadi.

\section{KESIMPULAN}

Tat Twam Asi adalah ajaran kesusilaan tanpa batas yang merupakan filsafat Agama Hindu. Ajaran Tat twam Asi ini dinyatakan identik dengan sila keprimanusiaan dalam Pancasila. Dinyatakan pula bahwa jika di cermati secara sungguh - sungguh, konsepsi sila perikemanusiaan dalam pancasila merupakan realisasi dari ajaran Tat Twam Asi yang terdapat dalam Kitab Suci Weda. Pentingnya ajaran Tat Twam Asi dalam kehidupan bermasyarakat, yaitu untuk menjaga hubungan antar saudara, keluarga dan linggkungan masyarakat. Betapa pentingnya Ajaran Tat Twam Asi dalam kehidupan kita untuk mencapai keharmonisan serta kedamaian

Kebahagian sejati adalah kebahagian yang sesuai hati nurani.Jadi berbahagialah orang yang mempunyai Suputra,karena putra yang berbudi luhur lebih mulia dari pada melaksanakan $\quad 100 \quad$ yajna.Selalu mengingatkan diri kita agar menjadi orang waras, menghindari kejahatan dan meningkatkan kesadaran diri pribadi menjadi manusia yang selalu melaksanakan subha karma agar memperoleh kehidupan yang baik.Dan menghindari amarah karena amarah sungguh hina derajatnya, sangat merugikan 
diri sendiri, patut diatasi dengan pengendalian diri sebaik-baiknya, serta dengan menerapkan konsep kasih sayang sedalam-dalamnya ( tat twam asi ).Utamakanlah kejujuran dan berbahagialah selalu. Ingatlah bahwa jujur ( Arjawa ) adalah salah satu tuntunan susila untuk hidup bahagia, termasuk dalam Dasa Yama Bratha ( 10 macam pengendalian diri ) dan, kesabaran ini sangat perlu dicermati , dihayati dan diterapkan sebagaimana mestinya sehingga menjadi salah satu sifat unggulan yang akan mempengaruhi untuk mencapai kebahagian hidup.

\section{DAFTAR PUSTAKA}

Lilik, \& Mertayasa, I. K. (2019). Esensi Tri

Hita Karana Perspektif Pendidikan Agama Hindu. Bawi Ayah: Jurnal

Pendidikan Agama Dan Budaya Hindu, 10(2), 60-80.

Mertayasa, I. K. (2020b). Tat Twam Asi :

Landasan Moral Untuk Saling Asah, Asih Dan Asuh. In Beragama Dalam Damai (pp. 85-100). Jayapangus

Press Books. 